\title{
The DEBIT trial: an intervention to reduce antipsychotic polypharmacy prescribing in adult psychiatry wards - a cluster randomized controlled trial
}

\author{
A. Thompson ${ }^{1}$, S. A. Sullivan ${ }^{1 *}$, M. Barley ${ }^{1}$, S. O. Strange ${ }^{1}$, L. Moore ${ }^{2}$, P. Rogers ${ }^{3}$, A. Sipos ${ }^{1}$ \\ and G. Harrison ${ }^{1}$ \\ ${ }^{1}$ Academic Unit of Psychiatry, University of Bristol, Bristol, UK \\ ${ }^{2}$ Cardiff Institute of Society, Health and Ethics, Cardiff University, Cardiff, UK \\ ${ }^{3}$ School of Care Sciences, University of Glamorgan, Pontypridd, UK
}

Background. Clinical guidelines advise against prescribing more than one antipsychotic with limited exceptions. Despite this, surveys continue to report high antipsychotic polypharmacy rates. The aim of the study was to investigate the effectiveness of a multi-faceted intervention in reducing prescribing of antipsychotic polypharmacy on general adult psychiatry wards, compared with guidelines alone.

Method. A pragmatic cluster randomized controlled trial recruited 19 adult psychiatric units (clusters) from the South West of England. Participants were all ward doctors and nurses. The multi-faceted intervention comprised: an educational/CBT workbook; an educational visit to consultants; and a reminder system on medication charts.

Results. The odds of being prescribed antipsychotic polypharmacy in those patients prescribed antipsychotic medication was significantly lower in the intervention than control group when adjusted for confounders (OR $0.43,95 \% \mathrm{CI}$ $0.21-0.90, p=0.028$ ). There was considerable between-unit variation in polypharmacy rates and in the change in rates between baseline and follow-up (5 months after baseline).

Conclusion. The intervention reduced levels of polypharmacy prescribing compared to guidelines alone although the effect size was relatively modest. Further work is needed to elicit the factors that were active in changing prescribing behaviour.

Received 11 January 2007; Revised 14 June 2007; Accepted 2 July 2007; First published online 10 September 2007

Key words: Antipsychotics, evidence-based guidelines, polypharmacy, randomized controlled trial.

\section{Introduction}

There is very little evidence regarding efficacy of combining antipsychotics in the treatment of schizophrenia and there are a number of theoretical risks involved in such practice (Freudenreich \& Goff, 2002; Stahl, 2002). Several national guidelines on the treatment of schizophrenia have advised against the general use of more than one antipsychotic for the treatment of schizophrenia (Canadian Psychiatric Association, 1998; NICE, 2002; McGorry et al. 2003; APA, 2004). Despite this a UK cross-sectional survey in 1998 of in-patient wards found a rate of antipsychotic polypharmacy of $48 \%$ (Harrington et al.

* Address for correspondence: Ms S. A. Sullivan, Academic Unit of Psychiatry, University of Bristol, Bristol BS6 6JL, UK.

(Email: sarah.sullivan@bristol.ac.uk)
2002). Similar high rates have also been found in international studies (Ereshefsky, 1999).

There is widespread recognition that dissemination of guidelines and research evidence alone does not change behaviour nor ensure sustainable changes in practice (Bero et al. 1998) and therefore implementation strategies are needed. The evidence on the effectiveness of different strategies to promote the implementation of research findings or clinical practice guidelines suggests that interventions most likely to be effective include: educational outreach visits ('academic-detailing'), computerized and manual reminders and interactive educational meetings (Oxman et al. 1995; Bero et al. 1998); as well as multi-faceted approaches (Bero et al. 1998; Wensing et al. 1998). Trials that address the specific barriers to change and embrace psychological models of behaviour change appear to be a theoretically attractive option (Chilvers 
et al. 2002). There have been no guideline implementation trials in the field of psychiatry in the UK and indeed a recent article suggested the need for such a trial focusing on antipsychotic polypharmacy (Ito et al. 2005).

The aim of the DEBIT (Developing Evidence-Based Implementation Trial) study was to evaluate the effectiveness of a multi-faceted intervention to reduce inappropriate antipsychotic polypharmacy prescribing on psychiatric in-patient wards compared with guideline dissemination alone.

\section{Method}

\section{Study design}

We recruited four local mental health Trusts (service provider organizations) in the South West of England based upon their geographic proximity to the research base in Bristol. They covered a mixed urban and rural area with a population of $\sim 4$ million people. The study received full multi-centre ethics approval. Consent for the study was obtained from each Trust's Medical Director and Chief Executive (acting as 'guardians' of the cluster). The study was adopted by each Trust's clinical governance (quality assurance programme) committee, the Trusts receiving guidance from the research team as required. There were 19 acute psychiatric units (each with two or more wards) that admitted general adult psychiatry patients within these four Trusts. Wards that had solely a specialist psychiatry function (e.g. rehabilitation and forensic psychiatry wards) were excluded from the study but all other wards, including wards whose function was designated psychiatric intensive care (PICUs) and high dependency (HDUs) were eligible. Individual consent to examine medication charts was obtained from all but one of the consultant psychiatrists who admitted patients to these wards.

We used a cluster randomized design as the intervention was aimed at doctors and nurses but the outcome measures were taken from individuals under the care of these clinicians. Our unit of randomization (cluster) was the acute psychiatric unit. We chose the unit rather than individual wards in order to avoid contamination of results caused by staff moving between the different wards in the same unit. To ensure that the control and intervention groups were balanced with respect to factors likely to influence the outcome, stratified randomization was used based upon size of unit, measured as number of beds [divided into a binary variable, large ( $>40$ beds) or small ( $\leqslant 40$ beds)] and by the four Trusts. From our preparatory prescribing survey we found a large variation in prescribing patterns. Allocation to control and intervention was by random numbers generated by L.M. (using a calculator's random number generator function), who was blind to the identity of these units. The timetable for the trial was designed to coincide with the 6-monthly rotation of psychiatric senior house officers in order to limit the potential for contamination caused by doctors moving between units. Recruitment of the Trusts and units occurred in October 2003 and baseline measures were taken in February 2004. The intervention occurred between March and July 2004, with follow-up measures taken in July 2004. Participants were all qualified medical and nursing staff working on the wards involved. Participants were potentially aware of which group (control or intervention) they were allocated to due to the nature of the intervention.

\section{Intervention}

The design of the intervention adhered to the Medical Research Council (MRC) guidance on complex interventions (MRC, 2000). The 'modelling phase' of the intervention was based on a review of the literature and our previous qualitative work, interviewing consultant psychiatrists and observation on two general adult wards (Barley et al. in press). This work identified the need to develop an intervention aimed at teams of professionals (nurses and doctors), as prescribing decisions were found to be influenced by multi-disciplinary team members and not made in isolation by individual consultant psychiatrists even though the nurses in our units were not yet able to prescribe. The intervention was multi-faceted as suggested by a number of reviews of implementation strategies (Bero et al. 1998; Wensing et al. 1998).

For the first part of the intervention, an educational outreach or 'academic-detailing' approach was used (Soumerai \& Avorn, 1990). This involved a 30-minute structured personal visit to consultant psychiatrists by a specially trained clinical psychiatric pharmacist. The structure of the visit was based on the social marketing principles of 'academic-detailing', described by Soumerai \& Avorn (1990). This included the use of graphical material, reinforcement of key messages and the use of prepared counter-arguments arising from previous interviews with consultant psychiatrists (Barley et al. in press). The pharmacist read prepared literature reviews of the current evidence and then received 2 days' training in academic-detailing and associated marketing techniques facilitated by A.T. and a local pharmaceutical company trainer. The pharmacist completed 'encounter forms' after every visit that were reviewed regularly for fidelity to the 
structure by A.T. and G.H. Due to the large distances involved, it became clear that it was not possible for all consultants to receive a follow-up visit in the period of the intervention. Therefore, the intervention consultants were randomly allocated, using a random number generator, for either a brief follow-up visit or telephone call to review progress on agreed targets.

For the second part of the intervention a workbook for both doctors and nurses was developed. This contained educational material and specific cognitive techniques to challenge polypharmacy. The cognitive behavioural techniques were based upon the principles of reducing risk taking behaviours (Forensic Psychology Practice Ltd, 1999; Rawson, 1999). Cognitive challenges to polypharmacy prescribing were identified from the rationales used by clinicians to justify polypharmacy (Barley et al. in press). A range of strategies as alternatives to polypharmacy was offered. The workbook was piloted on a local forensic psychiatry ward for time of completion (around 1 hour), ease of understanding and relevance to practice resulting in slight adaptations. The distribution of the workbook to all doctors and qualified nurses was coordinated by the ward manager. A brief feedback form was included at the back of the workbook for return, so that a measure of the completion rate might be calculated. Continuing Professional Development certificates were given on workbook completion. A 'booster' pamphlet was sent 8 weeks after distribution of the workbook.

For the third part of the intervention, a medication chart reminder system was developed. Ward pharmacists applied removable reminder stickers to medication charts when patients were prescribed more than one antipsychotic. Medication charts were scrutinized weekly and reminder stickers were removed if polypharmacy was no longer prescribed. Ward pharmacists were given a short training on the application of the reminder system. All the stickers were removed 3 weeks before the post-intervention primary outcome measure was collected to avoid biasing the data collectors.

Polypharmacy was defined as prescription of more than one antipsychotic medication [either as regular, as required ('prn') or once only medication]. Antipsychotic medication was defined by the relevant edition of the British National Formulary (Joint Formulary Committee, 2003, 2004).

\section{Control units}

In order to compare simple dissemination with our intervention, we developed a guideline on antipsychotic polypharmacy from a range of evidencebased sources, including the National Institute for
Clinical Excellence (NICE) guidelines on the treatment and management of schizophrenia (NICE, 2002). This was disseminated to all doctors and nurses in both control and intervention clusters as per normal dissemination route for each Trust after baseline data was collected.

\section{Outcome measures}

The primary outcome measure was antipsychotic polypharmacy prescribing rates for each unit (cluster). Information was collected from patients' medication charts using a 1-day cross-sectional survey of antipsychotic prescribing pre- and post-intervention. All in-patients being prescribed any antipsychotic medication on the day of the surveys were included. Independent auditors collected the anonymized data using a pre-designed data-collection sheet. A list of antipsychotic drugs to be included in the audit was produced using the appropriate edition of the British National Formulary (Joint Formulary Committee, 2003, 2004). The auditors were Trust employees, who were not part of the research team, and were blind to randomization at baseline but not at follow-up and were aware of the purpose of the study. The auditors were given training in the correct collection of data and auditor reliability was checked by duplicating $15 \%$ of records. A questionnaire measuring nurses' and doctors' beliefs about polypharmacy was the secondary outcome measure and will be reported in a future publication.

\section{Sample size and data analysis}

Power calculations were based on data from a large retrospective case note survey in a local mental health Trust on antipsychotic polypharmacy, undertaken during 2001/2002 (Sipos, 2004). In this study we found a cross-sectional antipsychotic polypharmacy rate of $52 \%$. Sample size was based on the assumption of: a reduction of antipsychotic polypharmacy rates from $50 \%$ to $25 \%$ in the intervention group with no change in the control group; $90 \%$ power to detect a statistically significant difference with a type I error rate of 0.05 in a two-tailed test of differences between proportions. As the study was cluster-randomized we took account of this design effect. We used the casenote survey (Sipos, 2004) to estimate an intra-class correlation coefficient (ICC) of 0.027 (95\% CI 0-0.086). We calculated we would need 226 patients or 18 units based on an average of 13 observations per unit.

Primary and secondary analyses were undertaken using a pre-specified analysis plan. The primary outcome was analysed using a unit-level weighted regression analysis (Donner \& Klar, 2000). First, we calculated the ICC using baseline patient-level data, 
second, the unit (cluster) level data at baseline was used to calculate the weight for each unit using the formula of Donner \& Klar (2000, p. 88). The subsequent regression models were estimated on the cluster-level data using the logarithm of the polypharmacy rate in each unit at post-intervention as the dependent variable. We used an unadjusted model (Model A) which included stratifying variables (size of unit and Trust) as covariates, and a model (Model B) which also adjusted for the baseline proportion of antipsychotic polypharmacy in each unit. Additional post-hoc explanatory analyses not included in the prespecified plan were undertaken to further adjust for variations in case-mix. Variations between units were adjusted for by inclusion of a covariate measuring the proportion of specialist beds (mostly PICU and HDU beds) in each unit (Model C). Variations in casemix change across units over the study period were adjusted for by inclusion of covariates measuring change between baseline and post-intervention for (i) those who were male, (ii) age (at survey time point), (iii) median length of stay (up to survey point) (Models D and E). All analyses were undertaken using Stata version 8.0 (StataCorp, College Station, TX, USA).

\section{Results}

\section{Participants and patients}

There were 474 patients prescribed at least one antipsychotic in the baseline survey and 488 at follow-up. More patients were prescribed at least one antipsychotic in the intervention arm units than the control arm units both in the baseline and follow-up surveys. Of the participants, 112 doctors and nurses left during our intervention period (47 from the control and 65 from the intervention units) (Fig. 1).

\section{Characteristics of units}

The characteristics of these units are shown in Table 1. There were more specialist beds in the intervention group units but otherwise the groups were reasonably balanced between the trial arms.

The baseline and follow-up characteristics of the patients whose medication charts were sampled in the control and intervention units are shown in Table 2 along with the corresponding rates of antipsychotic polypharmacy. Patients were younger, more likely to be male and detained under the Mental Health Act (although this information was not available from all units) in both baseline and post-intervention survey in the intervention arm. This may have been due to the higher number of specialist intensive care/high dependency beds in the intervention arm which may be more likely to admit young male patients detained under the Mental Health Act.

There was a higher proportion of polypharmacy at baseline in the intervention group (13\% greater than the control group). There was a decrease in prescribed polypharmacy rates in the intervention units $(7.4 \%)$ and an increase in prescribed polypharmacy rates in the control units $(7.0 \%)$ with an overall $14.4 \%$ difference in change between the two time periods.

There was considerable variation in the change proportions for the intervention units with all but three units showing a reduction in polypharmacy (ranging from a reduction of $26 \%$ to and an increase of $7 \%$ ). There was similar variation in the control units (ranging from an increase of $38 \%$ to a decrease of $10 \%$ ) with only two units having a lower polypharmacy proportion than at baseline (see Table 3).

\section{Weighted regression analysis}

The intra-class correlation for polypharmacy rates at baseline was 0.036 (95\% CI 0-0.083). The adjusted odds ratio (accounting for stratifying variables of unit size and Trust) of being prescribed antipsychotic polypharmacy in the intervention group was estimated as 0.74 (95\% CI 0.35-1.56, $p=0.40)$. With adjustment for baseline polypharmacy rates, the odds ratio was estimated as 0.43 (95\% CI $0.21-0.90$, $p=0.028$ ).

Further adjustment for the proportion of specialist beds in each unit, and for change in case-mix measured by change in length of stay increased the magnitude of the estimated effect and its statistical significance. Model E further adjusted for change in case-mix by gender and age, and similarly the effect size was not greatly altered with the results of the model still being significant at the 0.05 level. These analyses are shown in Table 4.

\section{Process monitoring}

For the educational outreach component the mental health pharmacist was able to visit 51/55 (92.7\%) of the consultants in the intervention units at least once, of these $24(43.6 \%)$ had a follow-up visit or phone call. The average time spent per consultant was $31.7 \mathrm{~min}$ (range 20-60 $\mathrm{min}$ ). The numbers returning the feedback form gave an estimate of how many people completed the workbook. This was $50 \%$ with proportionally more nurses than doctors completing the workbook feedback form (52\% compared to $45 \%$ for doctors). There was also a space for free text feedback on the workbook feedback form. This feedback was mostly favourable, but was not quantifiable. We also performed a 1-day random check of the coverage of the reminder system. The percentage of charts where 


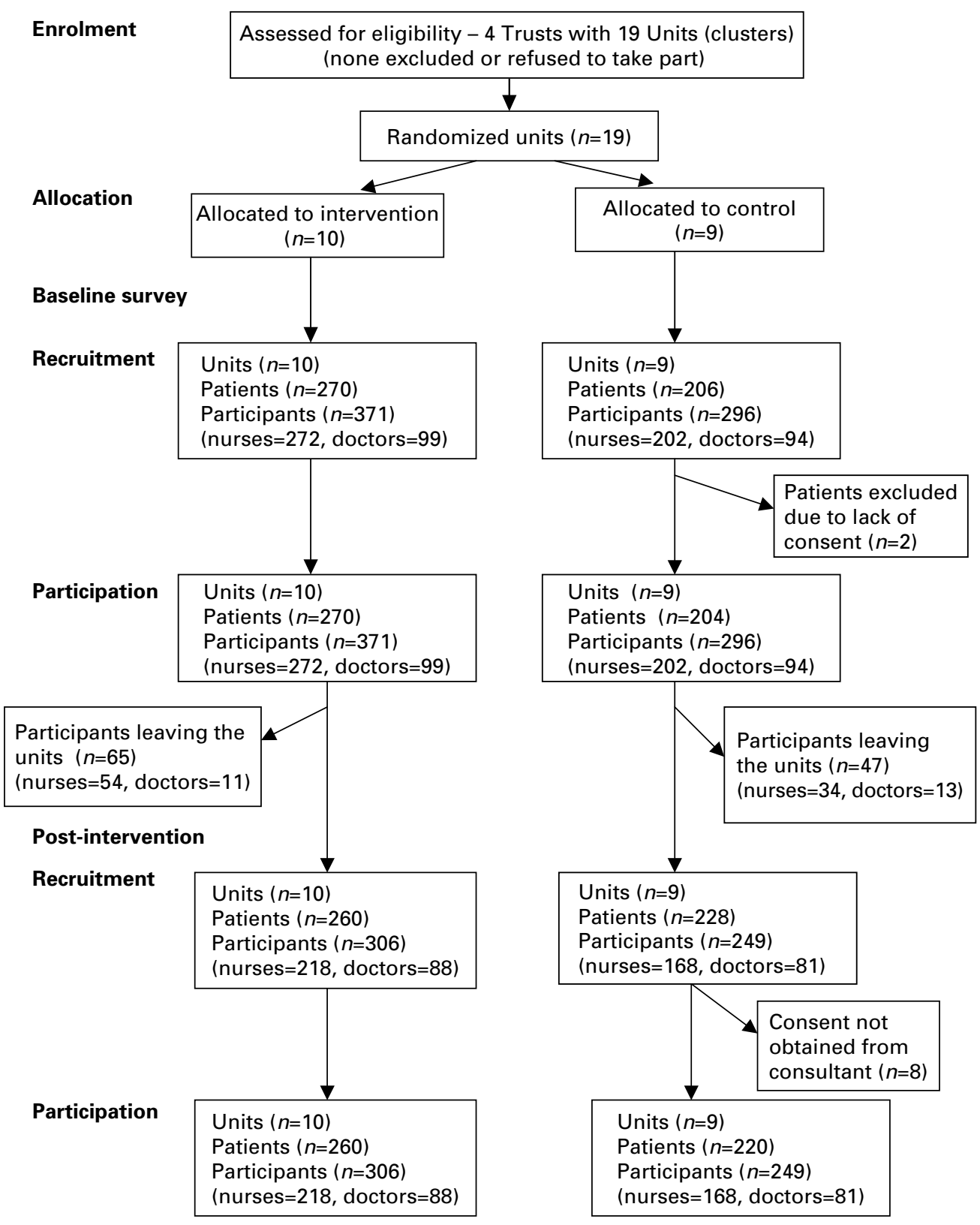

Fig. 1. Flow of in-patient units, patients (for outcome survey) and participants through the trial.

stickers were appropriately used when patients were prescribed antipsychotic polypharmacy was $61 \%$ (Trust range $45.2-100 \%$ ). The check of the reliability of the Trusts' data collectors in using the photocopied medication charts, in terms of correctly coding polypharmacy, was $100 \%$.

\section{Discussion}

Our multi-faceted intervention, aimed at ward doctors and nurses, significantly reduced the odds of being prescribed antipsychotic polypharmacy, compared with a control group who received a set of guidelines. However, the effect size was modest and must be evaluated in the light of a relatively intensive intervention package.

Multi-faceted interventions, especially those addressing specific barriers to change, appear to be the most effective method of improving professional practice (Bero et al. 1998; MRC, 2000). A review of interventions to change doctors' prescribing behaviour suggests that this may be less clear for prescribing 
Table 1. Characteristics and comparisons of the units (clusters) involved in the trial by control and intervention arms

\begin{tabular}{lll}
\hline & Control & Intervention \\
\hline $\begin{array}{l}\text { Number of units } \\
\text { Mean bed numbers/unit size }\end{array}$ & 9 & 10 \\
$\quad$ Overall & $39(17-63)$ & $38.2(16-65)$ \\
$\quad$ Trust A (range) & $47.5(33-63)$ & $42.25(28-65)$ \\
$\quad$ Trust B (range) & $28.5(17-40)$ & $43(34-48)$ \\
Trust C (range) & $53(53-53)$ & $36(36-36)$ \\
Trust D (range) & $25.5(25-26)$ & $24(16-32)$ \\
Stand-alone PICU units (beds) & $2(12)$ & $3(35)$ \\
Total PICU/HDU beds & 15 & 60 \\
Total specialist beds & 18 & 86 \\
Mean number of specialist beds & $3.44(0-12)$ & $7.80(0-21)$ \\
(range) & & $0.92(0.53-1.33)$ \\
Mean staff/bed (range) & $0.85(0.65-1.59)$ & $0.28(0.12-0.56)$ \\
Mean doctor/bed (range) & $0.27(0.08-0.47)$ & $0.65(0.38-0.86)$ \\
Mean nurse/bed & $0.58(0.35-1.12)$ & $4 / 6$ \\
(range) & & $-0.25(-6.73$ to 14.19$)$ \\
Stand-alone psychiatric unit/part & $4 / 5$ & 6 \\
of general hospital & & \\
Mean Townsend deprivation score & $-0.24(-5.57$ to 10.87$)$ & \\
(range) & & \\
Units with dedicated ward clinical & 5 & \\
pharmacy services & & \\
\hline
\end{tabular}

PICU, Psychiatric intensive care units; HDU, high-dependency units.

behaviour alone (Gill et al. 1999). It has been suggested that a more 'psychological approach' to designing trials should take into account the literature on behaviour change (Chilvers et al. 2002). As part of the preparation for this trial we therefore examined barriers to change in consultants and nurses and how prescribing decisions are made using qualitative methods (MRC, 2000). We then incorporated these into both a social marketing technique and a cognitive behavioural approach.

Both academic-detailing and the use of reminder systems have a fairly robust evidence base in terms of implementing change in clinical practice and in prescribing behaviour (Grimshaw et al. 2002; Thomson O'Brien et al. 1997). What is novel to this trial is the adoption of a psychological model of prescribing with analogies to the stages-of-change model (Prochaska \& DiClemente, 1986). Using a workbook we attempted to provide a cognitive rationale for understanding polypharmacy, incorporating targeted cognitive challenges and behavioural experiments.

Implementation strategies in the area of prescribing have traditionally been aimed at pharmacists and doctors (Van Eijk et al. 2001). Our preparatory work highlighted the role played by nurses in the prescribing process and our approach of targeting both nurses and doctors appears to be novel in this field. Feedback data showed the interventions were well received.

\section{Generalizability}

The cross-sectional rate of polypharmacy at baseline in this study $(42.2 \%)$ is similar to the findings of the Royal College of Psychiatrist's multi-centre UK-wide audit, which reported that $48 \%$ of all patients prescribed more than one antipsychotic medication on a 1-day survey in 1998 (Harrington et al. 2002). Our clusters were all from the South West of England but we have no reason to believe that prescribing practices are significantly different in other parts of the country. Indeed the Trusts involved covered a large geographical area and had a mixture of urban and rural catchment areas. Similar rates in in-patient settings have also been found by others researchers both in the UK and internationally (Ereshefsky, 1999; Taylor et al. 2000; Centorrino et al. 2002) although their appears to be some variation between different units (Harrington et al. 2002).

The approach of utilizing existing clinical governance strategies in this study suggests that the effect of this intervention may be generalizable to other Trusts without being too expensive or labour-intensive. Our 
Table 2. Characteristics of the patients whose charts were audited in the control and intervention arms at baseline and post-intervention and percentages of prescribed antipsychotic polypharmacy in control and intervention groups (with associated $95 \%$ confidence intervals accounting for clustering)

\begin{tabular}{|c|c|c|}
\hline & Control & Intervention \\
\hline \multicolumn{3}{|l|}{ Baseline survey } \\
\hline Age (yr) & $(n=202)$ & $(n=264)$ \\
\hline Mean (s.D.) & $43.6(16.0)$ & $40.0(14.1)$ \\
\hline Sex & $(n=202)$ & $(n=268)$ \\
\hline Male & 47.0 & 47.8 \\
\hline Female & 53.0 & 52.2 \\
\hline Mental Health Act status & $(n=199)$ & $(n=255)$ \\
\hline Detained & 37.6 & 48.6 \\
\hline Informal & 62.3 & 51.8 \\
\hline Length of admission in days & $(n=201)$ & $(n=252)$ \\
\hline Median (S.D.) & $52(338.8)$ & $50(147.6)$ \\
\hline Percentage polypharmacy & $(n=204)$ & $(n=270)$ \\
\hline (95\% CI corrected for clustering) & $34.8(22.9-46.7)$ & $47.8(41.8-53.8)$ \\
\hline \multicolumn{3}{|l|}{ Post-intervention survey } \\
\hline Age (yr) & $(n=211)$ & $(n=250)$ \\
\hline Mean (S.D.) & $42.4(15.6)$ & $42.2(13.3)$ \\
\hline Sex & $(n=220)$ & $(n=258)$ \\
\hline Male & 50.0 & 63.6 \\
\hline Female & 50.0 & 37.4 \\
\hline Mental Health Act status & $(n=167)$ & $(n=207)$ \\
\hline Detained & 47.3 & 54.6 \\
\hline Informal & 52.7 & 45.4 \\
\hline Length of admission in days & $(n=185)$ & $(n=250)$ \\
\hline Median (S.D.) & $40(101.8)$ & $48.5(179.5)$ \\
\hline Percentage polypharmacy & $(n=220)$ & $(n=260)$ \\
\hline (95\% CI corrected for clustering) & $41.8(30.8-52.8)$ & $40.4(27.0-53.8)$ \\
\hline
\end{tabular}

Numbers in parentheses demonstrate available data for each parameter (values are percentages unless otherwise specified).

interventions, with the exception of the educational outreach (which could be provided by Trust pharmacists with additional training) were relatively low cost. However the coverage of the intervention did depend to some extent on the sophistication of the clinical governance mechanisms in each Trust.

\section{Limitations of the study}

The main limitation of the study was the crosssectional nature of the primary outcome measure. This was highlighted by the increase in the control group polypharmacy rate, which may be an artefact of the sampling method. The magnitude and statistical significance of the net intervention effect is in part due to these increased polypharmacy rates in the control group, This was an unexpected finding [particularly given the stability of rates found locally over a 6-month period by Sipos (2004)] which may, in whole or part, be attributed to regression to the mean and should be interpreted with caution. However, the additional post-hoc explanatory analyses did not find any attenuation of the intervention effect when change in case-mix between baseline and post-intervention samples was included in the models. Additionally the effect of the intervention appeared to be strengthened when the imbalance in the proportion of specialist beds between the control and intervention arms was adjusted for. Ideally multiple and longer term followup measurements would need to be taken to disentangle intervention effects from other variations, but this was not possible within the timescale and budget of the project. This would also have proved difficult due to fact that many of the junior doctors receiving the intervention would have moved units at the end of the intervention and provided potential contamination effects in other units. Follow-up measurements would also help to distinguish whether the effect is sustained over time and not a temporary phenomenon. It must be stressed, however, that the results presented are from the a priori pre-specified analysis plan. We were not able to distinguish between 
Table 3. Proportions of patients prescribed antipsychotic polypharmacy (with respective numbers) for each unit in the control and intervention group (and for all units in each group) at baseline and post-intervention

\begin{tabular}{|c|c|c|c|c|}
\hline & $\begin{array}{l}\text { Baseline } \\
\text { (proportion) }\end{array}$ & $\begin{array}{l}\text { No. of } \\
\text { patients }\end{array}$ & $\begin{array}{l}\text { Post-intervention } \\
\text { (proportion) }\end{array}$ & $\begin{array}{l}\text { No. of } \\
\text { patients }\end{array}$ \\
\hline \multicolumn{5}{|l|}{ Control } \\
\hline Unit 1 & 0.50 & 14 & 0.55 & 22 \\
\hline Unit 2 & 0.36 & 14 & 0.43 & 14 \\
\hline Unit 3 & 0.48 & 42 & 0.54 & 37 \\
\hline Unit 4 & 0.36 & 36 & 0.26 & 42 \\
\hline Unit 5 & 0.46 & 13 & 0.54 & 13 \\
\hline Unit 6 & 0.50 & 20 & 0.48 & 23 \\
\hline Unit 7 & 0.09 & 33 & 0.24 & 37 \\
\hline Unit 8 & 0.21 & 14 & 0.41 & 17 \\
\hline Unit 9 & 0.22 & 18 & 0.60 & 15 \\
\hline All units & 0.35 & 204 & 0.42 & 220 \\
\hline \multicolumn{5}{|l|}{ Intervention } \\
\hline Unit 1 & 0.50 & 20 & 0.37 & 19 \\
\hline Unit 2 & 0.36 & 11 & 0.36 & 14 \\
\hline Unit 3 & 0.39 & 23 & 0.40 & 25 \\
\hline Unit 4 & 0.38 & 29 & 0.32 & 31 \\
\hline Unit 5 & 0.58 & 26 & 0.64 & 25 \\
\hline Unit 6 & 0.48 & 29 & 0.30 & 20 \\
\hline Unit 7 & 0.58 & 50 & 0.65 & 48 \\
\hline Unit 8 & 0.39 & 31 & 0.13 & 31 \\
\hline Unit 9 & 0.52 & 31 & 0.39 & 33 \\
\hline Unit 10 & 0.45 & 20 & 0.21 & 14 \\
\hline All units & 0.48 & 270 & 0.40 & 260 \\
\hline
\end{tabular}

Table 4. Weighted regression analysis models

\begin{tabular}{|c|c|c|c|}
\hline & OR & $95 \% \mathrm{CI}$ & $p$ value \\
\hline $\begin{array}{l}\text { Model A } \\
\text { Stratifying variables, only (unit size and Trust) }\end{array}$ & 0.79 & $0.39-1.57$ & 0.47 \\
\hline $\begin{array}{l}\text { Model B } \\
\text { Stratifying variables and baseline polypharmacy rate }\end{array}$ & 0.43 & $0.21-0.90$ & 0.028 \\
\hline $\begin{array}{l}\text { Model C } \\
\text { Stratifying variables, baseline polypharmacy } \\
\text { rate and proportion of specialist beds }\end{array}$ & 0.29 & $0.13-0.68$ & 0.008 \\
\hline $\begin{array}{l}\text { Model D } \\
\text { Stratifying variables, baseline polypharmacy rate, proportion } \\
\text { of specialist beds and change in median length of stay }\end{array}$ & 0.27 & $0.10-0.71$ & 0.014 \\
\hline $\begin{array}{l}\text { Model E } \\
\text { Stratifying variables, baseline polypharmacy rate, proportion of } \\
\text { specialist beds and change in median length of stay, gender and age }\end{array}$ & 0.23 & $0.05-0.95$ & 0.045 \\
\hline
\end{tabular}

OR, Odds ratio; CI, confidence interval.

Models D and E estimated using data from only 18 units since length-of-stay data not available for one unit (a control unit).

patients who were sampled in both surveys (as they had not been discharged or were readmitted) but we were able to estimate that this was a small percentage (around 5\%) of the total and therefore unlikely to greatly bias the effect of the intervention.
There were unequal rates of polypharmacy in control and intervention groups at baseline. This was adjusted for in the analysis, but because of time constraints of completing the trial during a junior-doctor 6-monthly rotation period, this could not be taken into 
account during randomization. Our data collectors were not blinded at post-intervention to whether the unit was an intervention or control unit, but they were independent of the study group and therefore had limited incentive to bias a positive result. Our reliability check of the data collection process also showed high accuracy. There was variable uptake of parts of the intervention in some units and only $50 \%$ of the staff in the intervention group sent back an evaluation form on the workbook (although the actual numbers completing the workbook may have been greater). As the trial was multi-faceted we aimed to influence the prescribing culture through a number of avenues but we acknowledge that getting staff to participate in this part of the intervention was difficult and may need further measures to improve this. This variable uptake may be a reason for the more modest effect given a relatively intensive intervention.

\section{Findings in relation to literature}

Whilst many studies have examined interventions to reduce prescribing behaviour in other specialities (Gill et al. 1999; Freemantle et al. 2002), few studies have looked at interventions to change prescribing behaviour in the field of psychiatry. Gill et al. (1999) reviewed the literature on changing doctors' prescribing behaviour and extracted all randomized control trials that dealt exclusively with physician prescribing and/or with professional intervention. They identified five studies in the area of psychiatry mostly set in the USA. Two of these were related to prescribing, the others to wider-reaching quality-improvement initiatives in depression and old-age psychiatry. A controlled trial of academic-detailing to reduce prescribing of antipsychotic drugs in nursing homes (Ray et al. 1987) showed no effect, the authors citing other factors in the nursing home as a potential reason for this negative result. However, Avorn et al. (1992) were able to use educational materials and audit and feedback to reduce the prescription of 'psychoactive drugs' in a similar population. Berings et al. (1994) were able to demonstrate a reduction in benzodiazepine prescription using a combination of drug information and outreach, but the setting was in general practice and not in psychiatry.

\section{Future work and implications}

We have demonstrated that our multi-faceted intervention is effective. It is often difficult to define the 'active ingredient' when implementing complex interventions (MRC, 2000), we now need to investigate which of the components of this intervention was most important in influencing prescribing behaviour. The large difference in change in some units compared to others warrants further work as to whether broad contextual factors as well as the individual are important. We also plan to further explore the effect of the intervention on the patterns of prescribed and administered polypharmacy.

A recent survey by the UK mental health charity Rethink (Hogman \& Sandamas, 2000) highlighted patients' concerns regarding antipsychotic prescribing, the side-effects experienced and the consequent effects on their lives. We believe that interventions such as this can influence the local prescribing cultures towards the standards of good practice that will benefit patient care.

\section{Clinical implications}

(1) A multi-faceted intervention embedded in local clinical governance mechanisms can reduce antipsychotic polypharmacy prescribing on adult psychiatric wards.

(2) Such interventions should include doctors, nurses and pharmacists.

(3) Large variations in prescribing change between units suggests that local political and cultural issues are also important in the prescribing process and should be addressed by further studies.

\section{Acknowledgements}

The authors thank Tim Peters for his help in data analysis, Glyn Lewis for his helpful comments on the study and all the participating clinicians in Avon and Wiltshire Partnership Trust, Gloucestershire Partnership Trust, Somerset Partnership Trust and Devon Partnership Trust. We thank Nicola Hovey, Graham Parton, Liz Davenport and James Marriot for providing liaison between the appropriate trusts, medical directors and nursing directors. We acknowledge Lilly Pharmaceuticals for their help in providing marketing selling training for the intervention. We also thank Joe Curran and Kevin Gournay for advice on the workbook and acknowledge the members of the Project Advisory Group: Paul Dieppe, Simon Guest, Graham Parton, Tony Soteriou, Susan O'Connor, Roger Pedley, Catherine Pope, Alison Fry, Harvey Rees, Rupa Chilvers and Dimitris Fouskakis. Funding was provided by the Department of Health, NHS Executive, South West.

\section{Declaration of Interest}

Professor Harrison and Professor Rogers have received honoraria from pharmaceutical companies for contributing to educational events. Dr Thompson and Dr Sipos have received financial support from pharmaceutical companies to attend educational meetings. 


\section{References}

APA (2004). Practice Guideline for the Treatment of Patients with Schizophrenia. American Psychiatric Association: Washington, DC.

Avorn J, Soumerai SB, Everitt DE, Ross-Degnan D, Beers MH, Sherman D, Salem-Schatz SR, Fields D (1992). A randomized trial of a program to reduce the use of psychoactive drugs in nursing homes. New England Journal of Medicine 327, 168-173.

Barley M, Pope C, Chilvers R, Sipos A, Harrison G (in press). Psychiatrists' attitudes to clinical practice guidelines for the pharmacological treatment of schizophrenia: a qualitative study. Journal of Mental Health.

Berings D, Blondeel L, Habraken H (1994). The effect of industry-independent drug information on the prescribing of benzodiazepines in general practice. European Journal of Clinical Pharmacology 46, 501-505.

Bero LA, Grilli R, Grimshaw JM, Harvey E, Oxman AD, Thomson MA (1998). Getting research findings into practice: closing the gap between research and practice: an overview of systematic reviews of interventions to promote the implementation of research findings. British Medical Journal 317, 465-468.

Canadian Psychiatric Association (1998). Canadian Clinical Practice Guidelines for the Treatment of Schizophrenia. Canadian Journal of Psychiatry 43 (Suppl. 2), S25-S40.

Centorrino F, Eakin M, Bahk W-M, Kelleher JP, Goren J, Salvatore P, Egli S, Baldessarini RJ (2002). Inpatient antipsychotic drug use in 1998, 1993 and 1989. American Journal of Psychiatry 159, 1932-1935.

Chilvers R, Harrison G, Sipos A, Barley M (2002). Evidence into practice: application of psychological models of change in evidence-based implementation. British Journal of Psychiatry 181, 99-101.

Donner A, Klar N (2000). Analysis of binary outcomes. In Design and Analysis of Cluster Randomised Trials in Health Research, pp. 79-110. Arnold: London.

Ereshefsky L (1999). Pharmacologic and pharmacokinetic considerations in choosing an antipsychotic. Journal of Clinical Psychiatry 60 (Suppl. 10), 20-30.

Forensic Psychology Practice Ltd (1999). Working with Sex Offenders. Forensic Psychology Practice Ltd: London.

Freemantle N, Nazareth I, Eccles M, Wood J, Haines A (2002). A randomised controlled trial of the effect of educational outreach by community pharmacists on prescribing in UK general practice. British Journal of General Practice 52, 290-295.

Freudenreich O, Goff DC (2002). Antipsychotic combination therapy in schizophrenia. A review of efficacy and risks of current combinations. Acta Psychiatrica Scandinavica 106, 323-330.

Gill PS, Makela M, Vermeulen KM, Freemantle N, Ryan G, Bond C, Thorsen T, Haaifer-Ruskamp FM (1999). Changing doctor prescribing behaviour. Pharmacy World and Science 21, 158-167.

Grimshaw JM, Eccles MP, Walker AE, Thomas RE (2002). Changing physicians' behavior: what works and thoughts on getting more things to work. Journal of Continuing Education in the Health Professions 22, 237-243.
Harrington M, Lelliott P, Paton C, Okacha C, Duffett R, Sensky T (2002). The results of a multi-centre audit of the prescribing of antipsychotic drugs for in-patients in the UK. Psychiatric Bulletin 26, 414-418.

Hogman G, Sandamas G (2000). A Question of Choice. NSF: London.

Ito H, Koyama A, Higuchi T (2005). Polypharmacy and excessive dosing: psychiatrists' perceptions of antipsychotic drug prescription. British Journal of Psychiatry 187, 243-247.

Joint Formulary Committee (2003). British National Formulary, 46th edn. British Medical Association and Royal Pharmaceutical Society of Great Britain: London.

Joint Formulary Committee (2004). British National Formulary, 47th edn. British Medical Association and Royal Pharmaceutical Society of Great Britain: London.

McGorry P, Killackey E, Elkins K, Lambert M, Lambert T (2003). Summary Australian and New Zealand clinical practice guideline for the treatment of schizophrenia. Australian Psychiatry 11, 136-158.

MRC (2000). A Framework for Development and Evaluation of RCTs for Complex Interventions to Improve Health. Medical Research Council: London.

NICE (2002). Guidance on the Use of Newer (Atypical) Antipsychotic Drugs for the Treatment of Schizophrenia. Technology appraisal Guidance No. 43. National Institute for Clinical Excellence: London.

Oxman AD, Thomson MA, Davis DA, Haynes RB (1995). No magic bullets: a systematic review of 102 trials of interventions to improve professional practice. Canadian Medical Association Journal 153, 1423-1431.

Prochaska JO, DiClemente CC (1986). Towards a Comprehensive Model of Change. In Treating Addictive Behaviours: Processes of Change (ed. W. R. Miller and N. Heather), pp. 3-27. Plenum Press: New York.

Rawson RA (1999). Treatment for Stimulant Use Disorders: Treatment Improvement Protocol (TIP) Series 33. Rockville, MD: U.S. Department of Health and Human Services.

Ray WA, Blazer DG, Schaffner W, Federspiel CF (1987). Reducing antipsychotic drug prescribing for nursing home patients: a controlled trial of the effect of an educational visit. American Journal of Public Health 77, 1448-1450.

Sipos A (2004). Preparing the way for evidence based implementation: A pharmacoepidemiological study of antipsychotic prescribing practice informing the design of a cluster randomised trial (Thesis). University of Bristol.

Soumerai SB, Avorn J (1990). Principles of educational outreach ('academic detailing') to improve clinical decision making. Journal of the American Medical Association 263, 549-556.

Stahl SM (2002). Antipsychotic polypharmacy: evidence based or eminence based? Acta Psychiatrica Scandinavica 106, 321-322.

Taylor D, Mace S, Mir S, Kerwin R (2000). A prescription survey of the use of atypical antipsychiotics for hospital inpatients in the United Kingdom. International Journal of Psychiatry in Clinical Practice 4, 41-46. 
Thomson O'Brien MA, Oxman AD, Davis DA, Haynes RB, Freemantle N, Harvey EL (1997). Educational outreach visits: effects on professional practice and health care outcomes. The Cochrane Database of Systematic Reviews, Issue 4. Art. No.: CD000409. doi:10.1002/14651858.

Van Eijk EC, Avorn J, Porsius AJ, de Boer A (2001).

Reducing prescribing of highly anticholingeric antidepressants for elderly people: randomised trial of group versus individual academic detailing. British Medical Journal 322, 654-657.

Wensing M, Van Der Weijden T, Grol R (1998).

Implementing guidelines and innovations in general practice: which interventions are effective? British Journal of General Practice 48, 991-997. 